\title{
As algaravias de Waly Salomão
}

\section{Roberto Zular}

Resumo: Em Alganaviast cámara de ecos, Waly Salomão problematiza a rede de questóes que emergiram da transformaçảo do campo literárío durante o processo de democratizaçào e globalizaçào daquele ainda recente final de século. Desde os "works in process" da década de 1970 (Me segura que eu vou dar um troço e os incríveis Babilaques) e a șua retomada na década seguinte (Gigolô de bibelòs e Armarinho de miudezas), constituiu a sua poética com um amálgama de ato, objeto e texto, Palavras-chave: Waly Salomão, forma da finitude, antientropia.

\footnotetext{
Abstract: In Algaravias: camara de ecos, Waly Salomão considers the transformation of the literary field during the democratization and globalization of that still recent end of the xx century. From the "works in process", of the seventies (Me segura que eu vou dar um troço and the incredible Babilaques), and its resuming in the next decade (Gigolo de bibelòs and Armarinho de miudezas), he made his poetry with an amalgamation of act, object and text. Keywords: Waly Salomão, the form of the finitude, anti-entropy.
} 
No panorama da poesia brasileira dos anos 1990, Algaravias: câmara de ecos, ${ }^{1}$ de Waly Salomão, chama a atenção pela problematização e complexidade formal com que trata a rede de questões que emergiram da transformação do campo literário correlata aos processos de democratização e globalização daquele ainda recente final de século. A quantidade de mal-entendidos e restos não resolvidos desses processos exigia um ouvido atento ao "canto das sereias", aos "pesadelos de classe", ao "poema jet-legged", ao "oco e cárie cava e prótese" com que o mundo paria e continua parindo o "defunto de sua sinopse".

Waly chega a esses anos desde uma longa viagem que se inicia na tropicália e atravessa um sem-fim de aventuras e desventuras nos vários papéis que desempenhou na cultura brasileira. Mas se trata de uma espécie de "sobrevivente" que abdica da construção de próteses memorialísticas dos sixties/seventies, do mesmo modo que não se submete à doxa reinante. As vozes que soam e ressoam em Algaravias alcançam uma camada de experiência mais sutil que elabora formas de relação com o passado e com a memória atentando para o presente de sua enunciação.

Se a experiência de Waly vinha permeada de um amálgama contraditório de contracultura e ditadura, liberação sexual e repressão, corpo e tortura, esse mesmo amálgama ressurge na experiência dos limites e possibilidades de certa liberdade contemporânea. É que, se o diagnóstico estiver certo, o Brasil sai do golpe militar com estruturas de controle disseminadas, inclusive pelo jogo de forças do mercado e do campo literários, que exigem um ouvido para o recalcado, para a dissipação melancólica de acomodações e constrangimentos, para a estranha familiaridade das nossas anomalias cotidianas. As promessas não cumpridas e os projetos abortados não se apagam assim tão fácil. Nesse sentido, Algaravias pode ser visto como uma espécie de re-escritura, sobretudo de Me segura que eu vou dar um troço, mas re-escritura que opera in loco, no corpo do poema, como revérbero de acúmulo de temporalidades e tensões que a excessiva presentificação do contemporâneo quer apagar.

Mas é claro que há uma "mudança de ar" e o outro antes visto como inimigo e invasor cede lugar a um diálogo e a uma abertura impensável até então, da qual resulta a admirável câmara de ecos. Por força de sua teatralização - o poema como ato, como palco, como máscara - na visão de Antonio Cícero, ${ }^{2}$ as vozes encenadas ganham

1 SALOMÃO, Waly. Algaravias: Câmara de ecos. São Paulo: Editora 34, 1996.

2 CICERO, Antonio. A falange de máscaras de Waly Salomão. In: Me segura qu'eu vou dar um troço. Rio de Janeiro: Aeroplano, 2003. Texto fundamental na bibliografia sobre Waly e que serve como diálogo constante deste artigo. 
corpo e amplitude a que só chega uma poética despida da violência identitária: são vozes que passeiam do outro ao mesmo até o "eu é um outro" de Rimbaud, do encantamento ao desespero, da plenitude ao vazio, da tela à rua, da rua ao mito e do mito ao mundo. Vozes tão desconfiadas quanto marcadas por uma forte afetividade, vozes num movimento contínuo de construção e desconstrução.

Mas essas vozes não pairam como puro desdobramento. Já na orelha-ensaio do livro, Davi Arrigucci apontava para a ambiguidade dissolvente que buscava trazer para $o$ poema a experiência tumultuária sem o centro fixo da identidade e dar forma "a um continuum espaço-tempo, mar sem margem". Se poesia é o "axial" ("Tal qual Paul Valéry"), é no poema como espaço que se quer autônomo, motivado até a última gota de sua fala, que Waly decide jogar seus dados.

Um poema ou mais de um: poemas configurando-se em um objeto antigo, cuja defasagem tecnológica tensiona as tecnologias da subjetividade que permeiam o mundo: "sempre sonhei em ser poeta de livro", conta Waly em uma entrevista a respeito de Algaravias. Em meio à voga da farsa realista, sonhar; no auge da escalada ponto.com, um livro; e não menos esquisito: ser poeta.

De fato, Algaravias é um livro de poemas. Como raros livros de poemas o são. Isto é, alcança um grau de imbricação entre suas partes que, se não pretendem ser um todo orgânico, exigem uma leitura atenta às reverberações internas que criam. "Après coup", nas malhas de uma dinâmica de ressignificação apontada por Freud, pode-se dizer que desde os "works in process" da década de 1970 (Me segura que eu vou dar um troço e os incríveis Babilaques) e sua retomada na década seguinte (Gigolô de bibelôs e Armarinho de miudezas), Waly constituiu sua poética com um amálgama de ato, objeto e texto. Creio que Algaravias é só mais um movimento dentro dessa poética que então se debatia com as formas da finitude: o verso, o poema, o livro.

Forma da finitude, o verso só se define como verso no momento em que termina. É o que diz Agambem em "O fim do poema." É possível pensar que o alcance de Algaravias se dê pelo fato de Waly não abrir mão dos problemas que se colocavam até então (não há um "retorno" a formas tradicionais), mas submetê-los a uma restrição formal que os comprimisse a ponto de fazê-los tornarem-se metáforas de si mesmos: o ato é mimese do ato, o teatro é de gestos implícitos, a citação é tutano e câmara de ecos, a escrita em processo torna-se imagem; em suma, a compressão transforma tudo em metáfora, “metáforas, metáforas, metáforas / metáforas à mancheia".

3 AGAMBEM, Giorgio. O fim do poema!. Cacto 1. São Paulo, 2002.

206. ZULAR, Roberto. As algaravias de Waly Salomão 
Quando a exceção se torna regra, o rigor formal impõe-se como uma barreira crítica antientropia. Mas o que pode a metáfora em tempos de simulacro? Encarnar-se em atos de fala. Organizar o movimento da fala, subjetivar esse movimento. ${ }^{4}$ Em suma, o veio central da mina, ritmo:

Hoje só quero ritmo.

Ritmo no falado e no escrito.

Ritmo, veio central da mina.

Ritmo, espinha-dorsal do corpo e da mente.

Ritmo, na espiral da fala e do poema.

Palavra sincopada, acelerando o encontro das consoantes (" $\mathrm{t}$ " $\mathrm{e}$ " $\mathrm{m}$ "), após um alongado e agudo "i" - ritmo e suas reiterações paralelísticas que se tecem no corpo e na mente, na fala e no escrito, na mina e na espinha dorsal. Trata-se, por todo o livro, de um ritmo que lida constantemente com a transformação das metáforas e trabalha com formas muito singulares de atenção que exigem corpo - quase sempre em sobressalto - e pensamento, olho e ouvido. Funciona em constante suspensão e nunca se sabe qual será o próximo elemento a organizar o movimento da fala: se a sonoridade, uma estrutura sintática, uma sequência de imagens, derivações semânticas ou o espaço da página. Esses sobressaltos, se têm o próprio poema como unidade última, pautam-se sobre a estrutura do verso e suas reiterações. $O$ verso se forma quando termina, mas a forma vive de sua retomada, das re-encenações do fim. Aquilo que volta para o mesmo ponto, mas já é outro: espiral. Aquilo que fala por escrito: poema. E que "provê um canto, um giro diverso para cada ato".

Aquilo que ouvimos quando lemos ganha corpo quase como quando ouvimos a "Fábrica do poema", momento forte do livro de Waly, na canção gravada por Adriana Calcanhoto em disco com o mesmo título. Pensamos em tudo o que o poema perde se for visto como um esqueleto asséptico e insosso de pura e racional escrita. Aquilo que se converte em pontos a serem decodificados por uma leitura muda. Ao contrário, o poema paradoxalmente almeja a canção ao mesmo tempo em que a recusa para ser poema. Almeja o corpo, a voz, mas aceita o jogo da mediação da escritura

4 Para Meschonnic, o ritmo é "organização do movimento da fala na linguagem por um sujeito". Ver, entre outros, Critique du rhythme: antropologie historique du langage. Paris: Verdier, 2002.

5 Cada ato que no limite implica "a resoluçāo de ser poeta / sem precisar o peito / estufar / de vãvaronice" (p. 28) 
e a massa de possibilidades discursivas que ela abre, quase como se a escrita fosse uma rasura reflexiva no universo da fala.

Se "Fábrica do poema", já pelo título, remete a uma tradição construtiva da poesia, a poética de Waly dá um nó no prumo da balança que, desde o artigo de Sérgio Buarque de Hollanda, vê a poesia brasileira num movimento que ora pende para a espontaneidade, ora para a construção. ${ }^{6}$ Waly lê os poetas a contrapelo do que dizem ou aparentam: o que há de mais forjado e construído que as "próteses da fantasmagórica Rua do Sabão" de Bandeira ("Rua Carioca 1993")? O que há de mais vivo e espontâneo que a reflexão tomada como uma "festa do intelecto" em Valéry ("Tal qual Paul Valéry")?? Para chegarmos à fábrica do poema, na arquitetura do livro (onde se apresenta entre duas fotos de Lina Bo Bardi), passamos por todo um caminho de poemas que abrem suas vozes para um diálogo com a tradiçāo literária, um dos sentidos fortes de "algaravias". Tanto por um longo amadurecimento do "velho louco por desenhar" na parábola de "Hokusai", quanto por uma abertura ao diálogo e à permeabilidade da fala:

\section{Câmara de ecos}

Cresci sob um teto sossegado, meu sonho era um pequenino sonho meu.

Na ciência dos cuidados fui treinado.

Agora, entre meu ser e o ser alheio

a linha de fronteira se rompeu.

Mas se o alheio vive quando é citado e se cada citação, conformada pelo ritmo próprio do poema, é uma nova enunciação, a literatura também se processa no limite entre fala e escrita, e o poema é, também nesse sentido, uma forma de agenciamento no corpo coletivo das enunciações. Quem cita rasura o passado, e a citação, como veremos, se torna uma metáfora do funcionamento da memória. É a citação tomada como ato:

6 HOLLANDA, Sérgio Buarque de. O lado oposto e outros lados. O espirito e a letra. São Paulo: Companhia das Letras, 1996.

7 A citação de Valéry constante nesse poema refere-se a um trecho de Tel Quel: "um poema deve ser uma festa do intelecto. Ele nāo pode ser outra coisa. Festa: é um jogo, mas solene, mas regrado, mas significativo; imagem daquilo que há de menos ordinário em nós, daquele estado onde os reforços são ritmos recompensados [...]. Terminada a festa nada pode restar. Cinzas, guirlandas pisoteadas." Oeuvres. Paris: Gallimard, 1958, p. 546, v. II, tradução minha.

208. ZULAR, Roberto. As algaravias de Waly Salomão 
"a substância do próprio tutano tornada citação". Daí que as menções a Cabral, Drummond, Bandeira, Ashbery, Camões etc. operem como balizas de um projeto de poesia e também como solo - espécie de espaço geográfico simbólico - iluminado de forma diferente por cada poema-viagem. A viagem como poema e o poema como crítica da viagem, algaravias e galáxias, ainda que aqui desponte por todo lado um tom melancólico de perda do sentido dos deslocamentos: "escrever é se vingar da perda" ("Poema jet-legged"). Mas cheguemos, enfim, a "Fábrica do poema":

sonho o poema de arquitetura ideal

cuja própria nata de cimento encaixa palavra por

palavra,

tornei-me perito em extrair faíscas das britas

e leite das pedras.

acordo.

e o poema todo se esfarrapa, fiapo por fiapo.

acordo.

o prédio, pedra e cal, esvoaça

como um leve papel solto à mercê do vento

e evola-se, cinza de um corpo esvaído

de qualquer sentido.

acordo,

e o poema-miragem se desfaz

desconstruído como se nunca houvera sido.

acordo!

os olhos chumbados

pelo mingau das almas e os ouvidos moucos,

assim é que saio dos sucessivos sonos:

vão-se os anéis de fumo de ópio

e ficam-se os dedos estarrecidos.

sinédoques, catacreses,

metonímias, aliterações, metáforas, oxímoros

sumidos no sorvedouro.

não deve adiantar grande coisa

permanecer à espreita no topo fantasma

da torre de vigia.

nem a simulação de se afundar no sono. 
nem dormir deveras.

pois a questão chave é:

sob que máscara retornará o recalcado?

(mas eu figuro meu vulto

caminhando até a escrivaninha

e abrindo o caderno de rascunho

onde já se encontra escrito

que a palavra "recalcado" é uma expressão

por demais definida, de sintomatologia cerrada:

assim numa operação de supressão mágica

vou rasurá-la daqui do poema.)

pois a questão chave é:

sob que máscara retornará?

Desde o primeiro verso, o sonho e a enunciação em primeira pessoa contradizem a fábrica e seu ideal de poema. No fim das contas, a enunciação se constrói referindo-se a um poema que não se escreveu, ainda que a memória da perda constitua a tessitura mesma do poema que estamos lendo. Enunciado e enunciação se chocam e o poema faz outra coisa que aquilo que diz. Eis um modo pelo qual a tradição encena a tensão entre voz e escrita. Não se trata, pois, de metalinguagem, mas de um modo de trapacear com a fala, de jogar com as astúcias da enunciação.

O poema também não deixa de apresentar um conflito romântico entre sonho e realidade, entre o leite da pedra e a faísca das britas, entre o poema-miragem e a cidade civil sonhada. Mas a formulação do problema é moderna: seria o poema ainda possível naquele final de século? Ou seria o artifício de sua desconstrução uma secreta despedida nostálgica? E tudo ainda seria simples não fosse o fato de o poema sonhado só sobreviver em fiapos, farrapos, ruínas e essa relação com o poema instaurar um modo de relação com o passado, com a memória, com as viagens, enfim, com o sujeito e o mundo. É que, neste contexto, ser um poeta construtivo significa que o poema se coloca como coisa entre coisas e é na forma da relação com ele, mais que no poema em si, que se instaura a significação. O poema paira ambiguamente como objeto que se busca e como objeto que instaura outra relação entre sujeito e mundo. O poema se encena em processo como construção de significação da impossibilidade de experiência da própria poesia, apenas pressentida pelo mingau das almas e os ouvidos 
moucos, sobrevivendo a si mesma com seus procedimentos fantasmagóricos (metonímias, aliterações, oxímoros), tudo se fundindo num mesmo torvelinho de perda e remorso, sugado nos sorvedouros da consciência embaçada e fluida das muitas formas de acordar ("acordo."/ "acordo,"/ "acordo?"/ "acordo!", se levarmos em consideração a pergunta final do poema).

O poema escrito com fósforos no "pergaminho da água do sono", numa sequência de rastros, registros obsessivos da "Persistência do eu romântico", recolhendo os cacos, cactos, das reentrâncias do poema e do mundo, forma uma amalgamada região de trópos "sem deixar pista de armazém,/ aparelho clandestino,/ ponta de estoque, local de resgate,/ arquivo ou fichário".

Vê-se aqui algo do drama drummondiano (a quem Waly renderia uma belíssima homenagem no seu magistral livro póstumo Pescados vivos). Nota-se desde a mesma estratégia de construção do sentido repleta de contradições performativas ("não rimarei a palavra sono / com a incorrespondente palavra outono" ${ }^{17}$ ), até o modo de perder as imagens pelo ralo da memória (as palavras "rolam por um rio difícil e se transformam em desprezo"9). Ou o diálogo explícito em que radicaliza: "o poeta é um ressentido e o mais são nuvens", “os ressentimentos esfiapados são como nuvens esgarçadas".

Em Algaravias, contudo, o ressentimento assume outra figura, a do recalque, transformado em metáfora da própria escrita, como rasura. É o que se evidencia nos longos parênteses que encenam o gesto da rasura. É ainda um jogo de re-escritura, procedimento central em Me segura e materializado nas imagens caligráficas dos cadernos fotografados nos Babilaques, mas aqui a busca pelo ato, como se disse, é mimese do ato - "e figuro meu vulto" - que faz do processo de escrita uma metáfora encenada no poema. A rasura sobre a palavra "recalcado" - sob que máscara retornará? - ativa uma estrutura subjetiva muito própria, tratada no excelente prefácio do livro, escrito por Antonio Medina Rodrigues e mais de uma vez aqui referido, embora só agora expressamente citado:

[...] a intimidade recalcada é uma das formas principais da poesia de Waly. Nela existe algo como o trauma da mãe, que abandona o recém-nascido na Estação da Luz, para deplorar esse ato pela vida afora. É por isso que a opção de Waly pela realidade retorna sempre sob a face de uma desventura desertada de todo e qualquer gozo.

8 ANDRADE, Carlos Drummond de. Consideração do poema. Nova reuniāo. Rio de Janeiro: José Olympio, 1987, p. 110.

9 Idem. Procura da poesia. Nova reunião, op. cit., p. 112. 
Mas desse recalque do recalcado - que se aproxima da estrutura psicótica descrita por Lacan ao buscar soluções imaginárias para recalcar (negar) o próprio recalcamento - por onde passa a câmara de ecos e suas máscaras, o que ficou fora surge em lampejos do real, como se aquilo que se tira do campo do simbólico ressurgisse nesse pela visão, ainda que alucinada, do mundo. Mas tudo isso, ressalte-se ainda uma vez, mimetizado nos poemas.

Algaravias de vozes (e tradição poética) são também câmaras de ecos entre mundo e ego, apresentados em Pescados vivos ${ }^{10}$ como palcos geminados. As soluções imaginárias, entre as quais o ego é apenas uma de suas máscaras, interpenetram ecos de ecos entre ego e mundo: "Absolutos que se refratam/ difratam.../ espelhos estilhaçados que não se colam", ${ }^{11}$ mas que se deflagram por meio de tubos alquímicos que percorrem os sucessivos recalcamentos e suas sucessivas máscaras.

O espaço do poema torna-se, assim, por esses mecanismos complexos, um espaço de construção que desfaz a falsa dicotomia entre mímesis e processo construtivo: trata-se de um espaço de mediação, mas que se realiza performativamente, criando aquilo que parece representar. Daí porque mundo e intertextualidade atuem no mesmo plano; a linguagem é tão real quanto o suposto real de que ela trata. Real que surge quanto mais as máscaras se mostram (como disse Lacan, a verdade tem a forma da ficção). Mas, sobretudo, o que se encena aqui, como já disse, é a própria enunciação. Não à toa, Ponge estará como epígrafe do livro seguinte de Waly, Lábia: ${ }^{12}$ é que a busca das palavras se confunde com a busca do objeto.

Os objetos de Waly, contudo, não são os objetos de Ponge (ou mesmo de outro poeta-referência, Cabral). A busca de Algaravias é uma busca quase épica, que se estende pela vastidão do mundo. ${ }^{13}$ Como em Me segura, o lugar privilegiado dessa busca é a viagem. Mas se ali a viagem vem carregada de conotações psicodélicas, ligadas às drogas e mesmo a uma saída para a situação de sufoco que marca os anos 1970 (lembremos que o Preço da passagem, de Chacal, da mesma época, remetia explicitamente à venda do livro para juntar dinheiro para sair do país), aqui a marca, como dissemos, é uma busca épica acidamente crítica ao estatuto da viagem no imaginário dos anos 1990.

10 SALOMÃO, Waly. Pescados vivos. Rio de Janeiro: Rocco, 2004.
11 Versos de "Barroco", op. cit., p. 11.
12 SALOMÃO, Waly. Lábia. Rio de Janeiro: Rocco, 1998.
13 RODRIGUES, Antonio Medina. Prefácio. In: SALOMÃO, Waly. Algaravias: Câmara de ecos, op. cit., p. 13.

212 - ZULAR, Roberto. As algaravias de Waly Salomão 
Em uma rápida pesquisa por Esses poetas, de Heloísa Buarque de Hollanda, pude constatar mais de dez poemas sobre viagens, em especial viagens internacionais, aos quais, de certa forma, Waly responde:

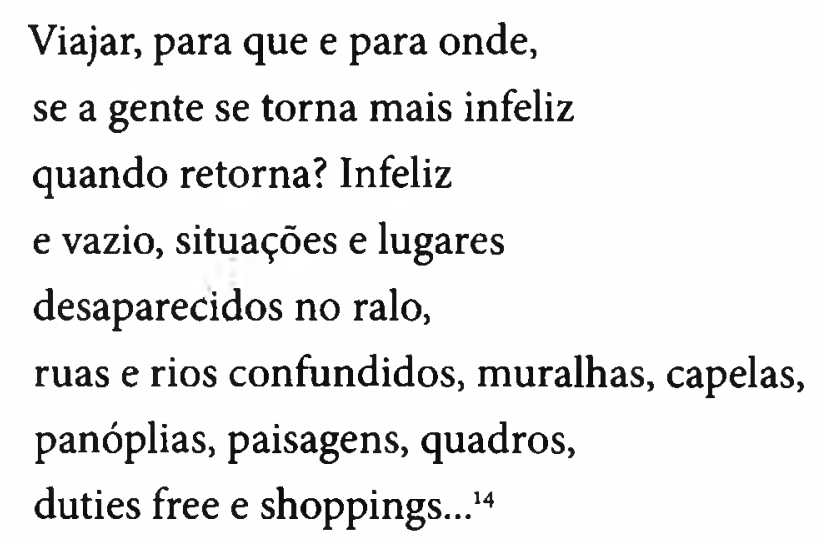

Se a busca é épica e o mote é a viagem, vê-se de pronto que esta se mostra incapaz de devolver um pouco que seja da experiência que se procura. É o que parece referir a foto da cidade natal de seu pai estampada na capa do livro. Mas não só as viagens internacionais são sugadas pelo rolo compressor da banalização, dos espaços previamente construídos. Como consta desde o título do sintomático "Pesadelo de classe":

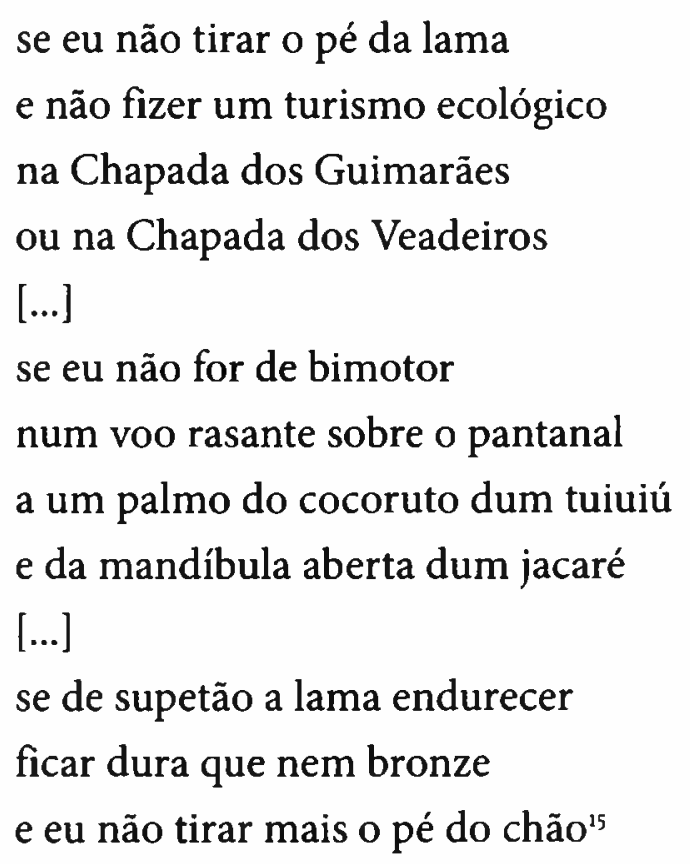

14 Versos do "Poema jet-lagged", op. cit., p. 29

15 Op. cit., p. 63. 
Esse pesadelo de classe confunde viagem com deslocamento. Viagem, no entanto, é estranhamento que pode estar no imaginário, na construção das máscaras, na percepção do recalcado, na fulguração do real, no despropósito banal de "enfiar o pé na jaca":

Não suba o sapateiro além da sandália

- legisla a máxima latina.

Então que o sapateiro desça até a sola

Quando a sola se torna uma tela

Onde se exibe e se cola

A vida do asfalto embaixo

$$
\text { e em volta. }{ }^{16}
$$

Como diz Lacan, "o real tem por propriedade carregar o lugar na sola dos sapatos" ${ }^{17}$ Esse estranhamento do lugar como fulguração imaginária dá a Waly uma percepção singular no panorama dos anos 1990. Enquanto, por exemplo, em um poema de Arnaldo Antunes a queixa é brigar contra a água, ou seja, a dificuldade de resistir quando não há enfrentamento, a estratégia de Algaravias é perpassada por uma escuta de novos modos diluídos de repressão, por uma escuta do recalque do recalcado, escuta de coisas que estão aqui ao lado, em torno: "água parada secreta veneno"

Desse "entorno" estranho e familiar resulta uma série de imagens ligadas a superfícies quase táteis corroídas pela ferrugem ou por camadas viscosas. Atuando ali sob nossos pés, como o "assoalho repleto das peles velhas das cobras/ e do pelo felpudo das aranhas caranguejeiras"18 São superfícies da pele do mundo que mudam de forma como Proteus, signo aqui das transformações da própria poesia. ${ }^{19} \mathrm{O}$ ritmo requer o tátil, e o tátil, a pele.

E da pele chegamos às incursões do corpo na escrita. Não só em virtude de o corpo perpassar a escrita mediado pelo ritmo, como também quando é do corpo que se trata. Se no Me segura a arte aparecia como expressão do corpo - "A arte é extensão do corpo. eu expliquei pro polícia tudo" -, aqui a estratégia é de "corpo fechado",

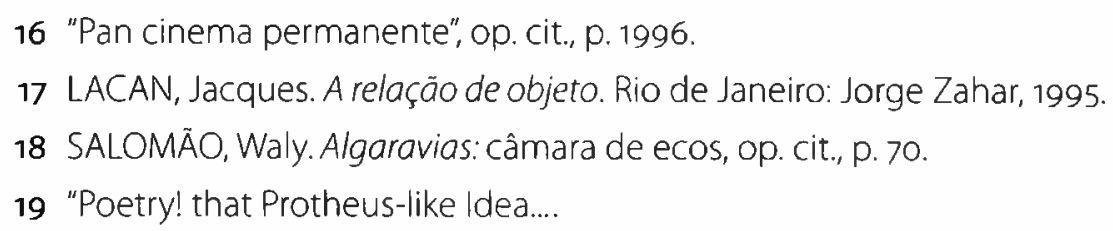


como respondendo a um modo de repressão que não diz mais 'não faça, não mostre', mas diz 'goze, exponha-se', tornando mais fácil o controle desse corpo assim exposto. Daí a releitura do mito homérico em "Canto de sereia":

(Primeiro movimento)

Tapar os ouvidos com cera ou chumbo derretido.

Construir uma fortaleza de aço blindado em volta de si.

O próprio corpo produzir uma resina que feche os poros, como o própolis faz nas fendas dos favos de mel. ${ }^{20}$

O corpo se fecha como que para impedir uma reconciliação que, ao final, redundaria em aniquilação. $O$ corpo nas reentrâncias das palavras. Esse fechamento, no entanto, como o das formas poéticas, é apenas um primeiro movimento de restrição (criada no próprio corpo do poema - a liberdade como possibilidade de se autoimpor restrições) para que algo surja pelas vozes filtradas na ilha de edição da memória que se projeta para o futuro:

Canto de sereia

(Segundo movimento)

A flor de estufa

salta a cerca

para luzir no mangue.

E se emprenha de fulano, sicrano e beltrano.

Sua vida atual reverbera vozes pretéritas,

adivinha vozes futuras.

[...]. ${ }^{21}$

Todo o movimento que descrevemos do recalque encontra-se nesses três primeiros versos que se abrem subitamente para o cortejo das vozes. Vozes que desse modo conquistadas alcançam momentos de puro deleite e graça como em "Minha alegria"

20 Op. cit., p. 75.

21 Op. cit., p. 77. 
ou na belíssima "quase-ode" "Mãe dos filhos peixes" e seu "duro doce mar divino". Vozes que por vezes se fazem ouvir como o vento "bêbedo de amnésia e desmemória" que "trafega indiferente a nossa tradição ibérica,/ que exige para tudo registro e certidão" cujo tabelião perfunctório reza:

"Lavro e dou fé... é verão"

$\mathrm{Ou}$

"Lavro e dou fé... é outono". ${ }^{22}$

Vozes que buscam, portanto, uma outra inteligência do real, longe de espaços institucionalizados, dos paraísos das chancelas; longe dos limites cartográficos da imaginação e dos que se julgam legitimados para instituir direitos alheios:

Nenhum habeas corpus

é reconhecido no Tribunal de Júri do Cosmos.

$\mathrm{O}$ ir e vir livremente

não consta de nenhum Bill of Rights cósmico.

Ao contrário, a espada de Dâmocles

para sempre paira sobre a esfera do mapa-múndi.

O Atlas é um compasso de ferro

demarcando longitudes e latitudes. ${ }^{23}$

A percepção do peso dessa espada de Dâmocles onde parecia haver apenas justos direitos e conhecimento desinteressado, simples geografia globalizada e sinais de novos tempos, confere ao espaço do poema uma força crítica insuspeitada. Vivemos num legalismo de exceção como vivíamos numa estranha ditadura legalista e a abertura internacional apenas restringiu a liberdade de um espaço de trânsito ainda há pouco desregrado. Essa diminuiçāo dos espaços sob a carapuça de estendê-los, essa ocupação vertiginosa de câmeras e leis, dá ao mundo uma "sensação de dejà vu/ que murcha qualquer frescor/ na idade madura". ${ }^{24}$

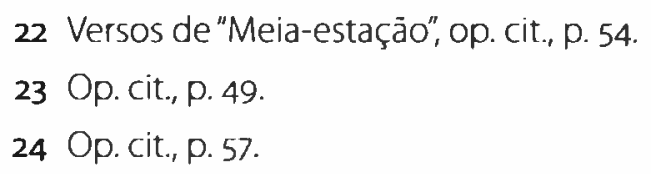


Resta à escrita haver-se com os restos, rastros que não figuram no moralismo das histórias, nem na aparente autoexplicação das imagens:

A vida não é uma tela e jamais adquire

o significado estrito

que se deseja imprimir nela.

Tampouco é uma história em que cada minúcia encerra uma moral.

Ela é recheada de locais de desova, presuntos, liquidações, queimas de arquivos,

divisões de capturas, apagamentos de trechos, sumiços de originais, grupos de extermínios e fotogramas estourados.

São inúmeras as sequências, por todo o livro, que, como essa última, multiplicam os lugares de dispersão, atando o funcionamento da memória à forma com que o mundo apaga os rastros para fazer a plástica de sua história. Nesses lugares recalcados - "o fantasmático país do olvido" - de perda e descaso, contudo, é que ainda restam talvez frestas para resgatar de algum modo o "humano fardo", mesmo que processado, com todas as implicações que vimos, numa ilha de edição:

Corrigindo:

o humano fado.

Roberto Zular é professor de Teoria Literária e Literatura Comparada na Universidade de São Paulo, autor de Escrever sobre escrever: uma introdução crítica à crítica genética (Martins Fontes, 2008). 